\title{
Some Aspects Regarding Torque Study and Elaboration of the Blades Orientation Mechanism for Microhydropower Plant
}

\author{
Bostan Viorel, Bostan Ion, Dulgheru Valeriu *, Ciobanu Oleg \\ Department of Fundamental Mashine Design, Technical University of Moldova, Chishinau, Republic of Moldova

\section{Email address:} \\ viorel.bostan@adm.utm.md (B. Viorel), ion.bostan@cnts.utm.md (B. Ion), valeriu.dulgheru@bpm.utm.md (D. Valeriu), \\ oleg.ciobanu@bpm.utm.md (C. Oleg) \\ ${ }^{*}$ Corresponding author
}

\section{To cite this article:}

Bostan Viorel, Bostan Ion, Dulgheru Valeriu, Ciobanu Oleg. Some Aspects Regarding Torque Study and Elaboration of the Blades Orientation Mechanism for Microhydropower Plant. International Journal of Mechanical Engineering and Applications. Vol. 8, No. 6, 2020, pp. 145-153. doi: 10.11648/j.ijmea.20200806.14

Received: November 3, 2020; Accepted: November 16, 2020; Published: December 8, 2020

\begin{abstract}
The analysis of hydraulic energy conversion systems has demonstrated the opportunity for the development of water kinetic energy conversion systems compared to potential energy conversion systems. Insistent searches of authors have led to the design and licensing of some advanced technical solutions for outflow micro hydroelectric power plants. They are based on the hydrodynamic effect, generated by the hydrodynamic profile of blades and by the optimal blades' orientation towards water streams with account of energy conversion at each rotation phase of the turbine rotor. The basic advantage of the flow microhydropower plant is the increase of the conversion efficiency by the simultaneous use of the pressure effects of water streams on the blade surface and of the hydrodynamic effect generated by the hydrodynamic profile of the blade with continuous blade orientation. The most important nodes of the microhydropower plant are the hydrodynamic rotor with vertical axis and the mechanism of continuous orientation of the blades depending on the direction of water currents. The paper makes an analysis of the brief torque and of the forces applied on the hydrodynamic blades located in the transition zone from the upstream area to the downstream area, by positioning the blades according to the flow velocity of the water flow which leads to increased hydrodynamics forces developed by each blade and the simultaneous reduction of the hydraulic resistance forces to the rotation of the blades, based on which the mechanism of orienting the blades in optimal positions against water currents was designed, developed, and manufactured.
\end{abstract}

Keywords: Micro Hydropower, Rotor, Hydrodynamic Profile, Hydrodynamic Coefficients, Torque

\section{Introduction}

The use of Renewable Energy Sources (RES) is a global priority, conditioned and argued by energy security, climate change and environmental protection and not at all for industrial and economic development.

Hydraulic energy is one of the most used RES, being one of the cheapest, quality and clean energy sources. As a renewable energy source, hydraulic energy can be obtained in two forms:

Potential energy (free fall of water);

Kinetic energy (flow of water currents).

The study of recent years shows that, due to low costs, large-scale hydropower is not a successful option for the future of energy production in developed countries, for various reasons, such as the environment, for example. The construction of dams on rivers has created major social and environmental problems. The artificial formation of huge water reservoirs by blocking the main arteries of the Earth has led to climate change and wildlife in the region, to the creation of sources of greenhouse gases.

A more efficient use of hydraulic energy, from the point of view of ecological and social impact, is the conversion of kinetic energy of flowing water of rivers, without the construction of dams by using flow microhydropower plants (floating), which are more cost effective, because they do not include essential costs related to civil constructions, wins in the competition on energy supply especially of isolated 
localities and objectives. The main advantages of micro-flow power plants: the relative simplicity of construction; the kinetic energy of the water is available 24 hours a day; they do not exert sonic pollution on the environment and are environmentally friendly. New laws on the environment affected by the danger of global warming consider obtaining energy from micro hydropower plants much more efficient.

The increase of the efficiency of the kinetic energy conversion of the water flow of the flow microhydropower plants with multipal hydrodynamic rotor is done by contributing to the formation of the summary torque of the hydrodynamic blades located in the transition zone from upstream to downstream, as well as by positioning the blades to the flow velocity of the water flow, leads to the increase of the hydrodynamic forces developed by each blade and to the concomitant decrease of the hydraulic resistance forces to the rotation of the blades $[1-3,5]$.

\section{Torque and Forces Applied on the Multipal Hydrodynamic Rotor}

In the following, we calculate the hydrodynamic coefficients for the reference profile NACA 0016 with length rope, for example $c=1,3 \mathrm{~m}$. The calculation methods described in $[4,8-10,13,16]$ are applied to calculate the coefficients corresponding to the profile NACA 0016 with rope length $c_{\text {ref }}=1 \mathrm{~m}: C_{L, \text { ref }}, C_{M, \text { ref }}$ and $C_{D, \text { ref }}$. The coefficients corresponding to the profile with the length rope are calculated from the relations (1):

$$
\begin{aligned}
& C_{L}=C_{L, \text { ref }} \cdot 1,3, \\
& C_{M}=C_{M, r e f} \cdot(1,3)^{2}, \\
& C_{D}=C_{D, \text { ref }} \cdot 1,3 .
\end{aligned}
$$

Figure 1 shows the values of the load and resistance coefficients depending on the angle of attack. Taking into account these values, we choose as the working angle of attack, the angle $\alpha=18^{\circ}$ (see also figures 2, 3).

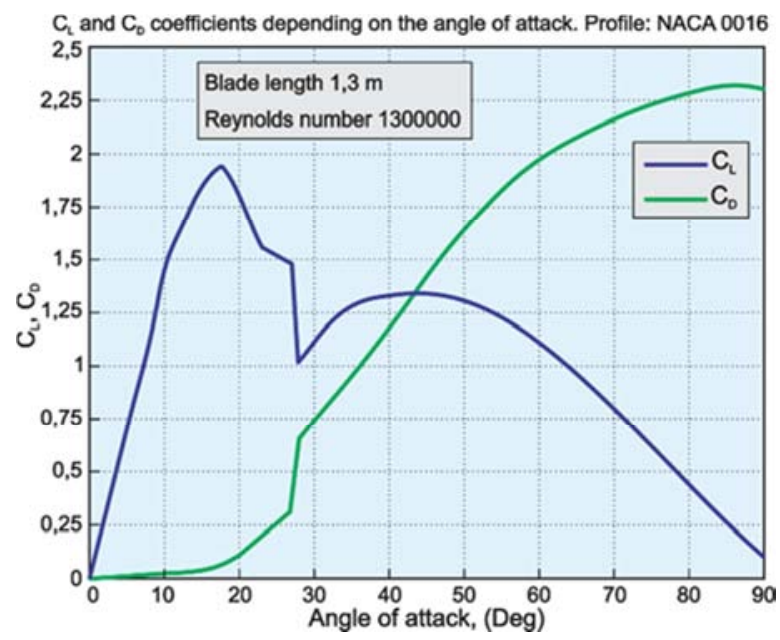

Figure 1. Hydrodynamic coefficients $C_{L}$ and $C_{D}$ depending on the angle of attack for the hydrodynamic profile NACA 0016.

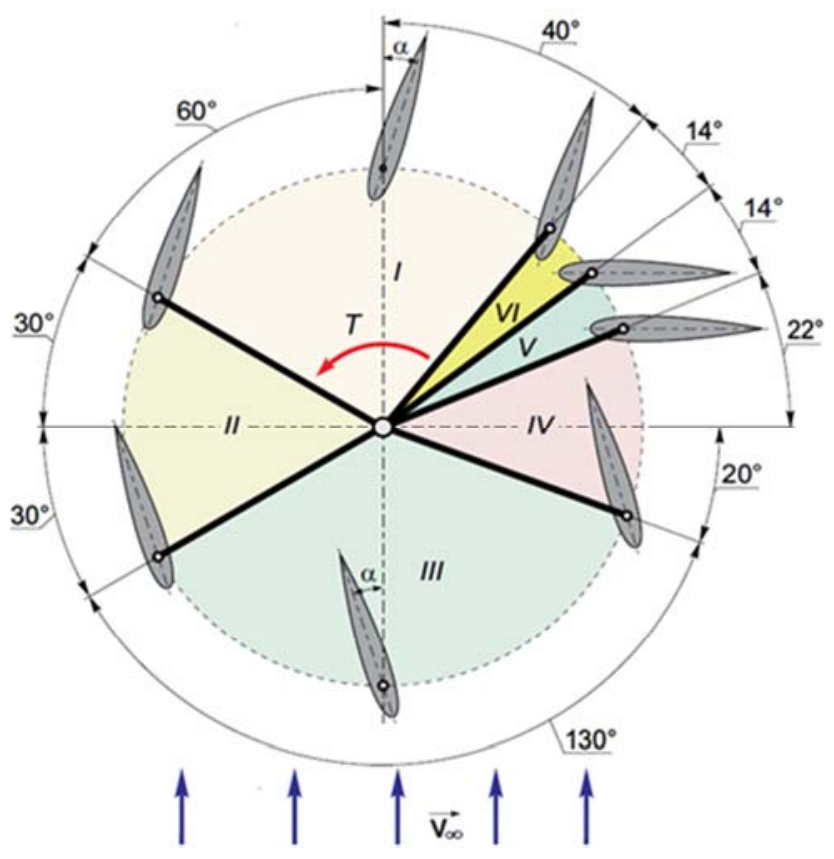

(a)

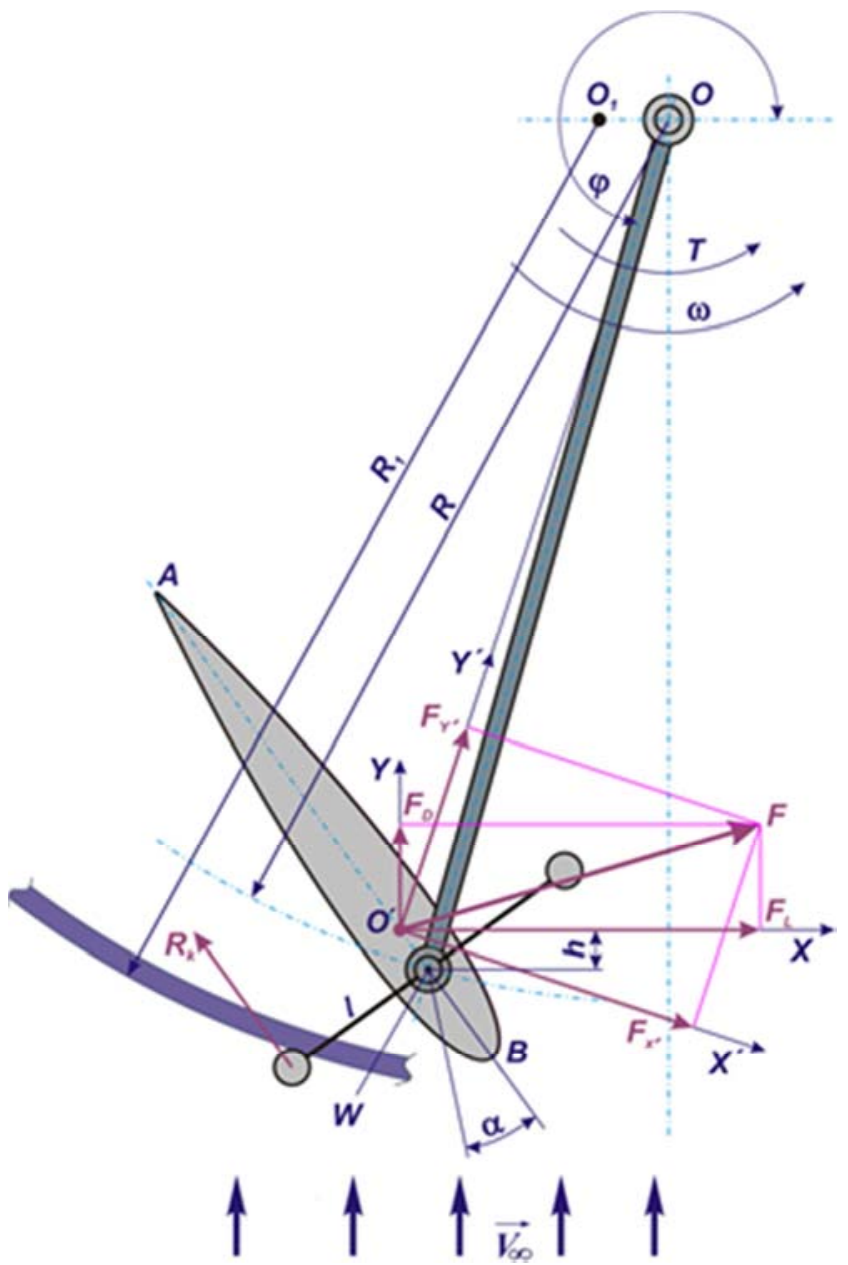

(b)

Figure 2. Blade positions and working areas (a), blade with hydrodynamic profile (b). 


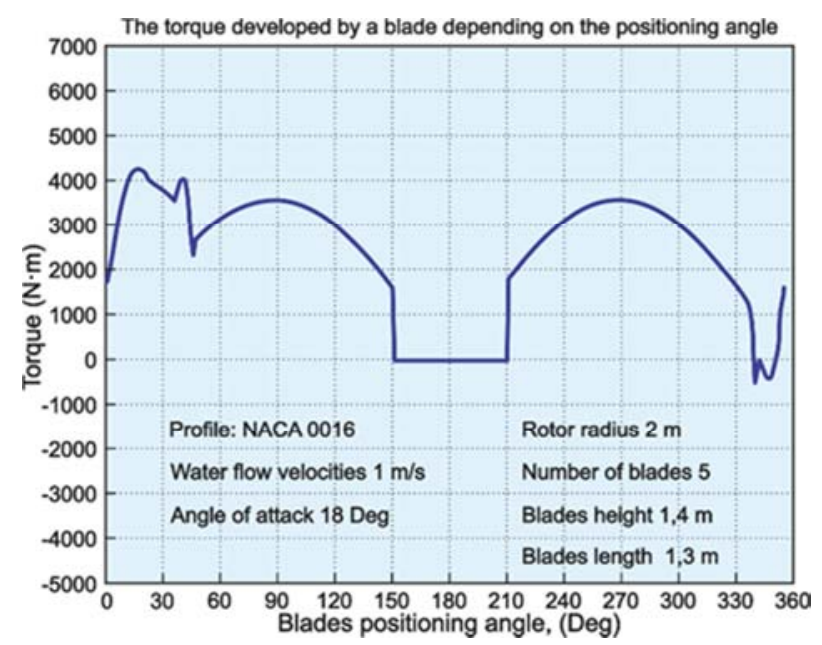

(a)

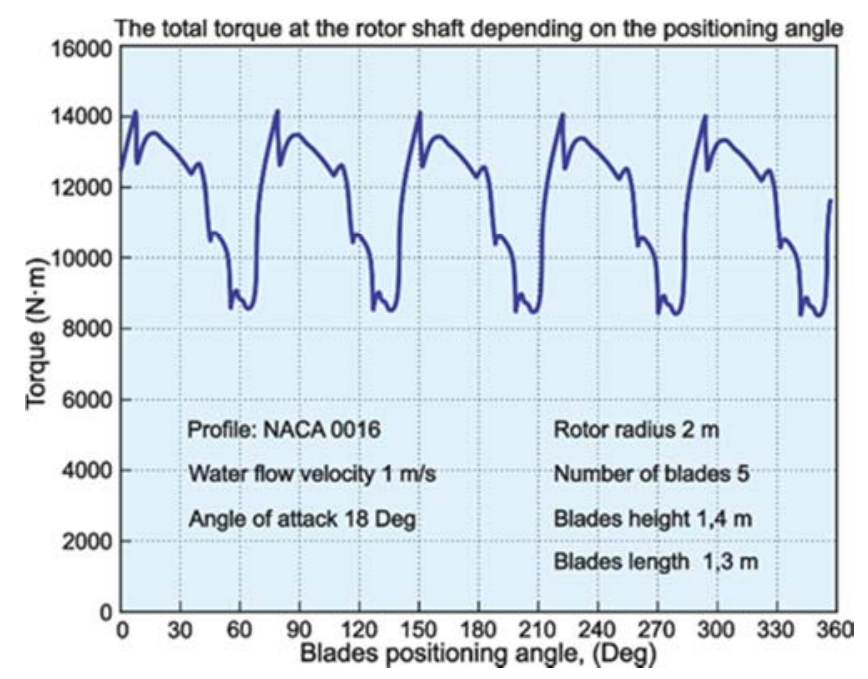

(b)

Figure 3. The moment $T_{r, i}$, developed by a rotor blade according to the positioning angle (a), the total moment $T_{r \Sigma}$ developed by 5 blades at the rotor shaft according to the positioning angle.

During its movement, the blade changes its angle of attack depending on its position (figure 2 (a)). Thus, in sector I, the angle of attack (the angle formed by the blade and the water current) is $18^{\circ}$; In region II, the angle of attack changes from $18^{\circ}$ to $-18^{\circ}$, but the blade does not contribute to the total moment developed at the rotor shaft. In this sector, extended to about $60^{\circ}$ the blade is carried free by the water current, and its repositioning at the angle of $-18^{\circ}$ takes place at the end of sector III. In Sector III, the angle of attack is $-18^{\circ}$. In sectors IV - VI the hydrodynamic effect is minimal, and the blade is to be repositioned from angle $-18^{\circ}$ to angle $18^{\circ}$. In order to use the kinetic energy in sectors IV - VI, it was proposed to reposition the blade in sector IV from $-18^{\circ}$ to $90^{\circ}$, in sector $\mathrm{V}$ the blade remains below the angle $90^{\circ}$, and in sector VI the angle of attack returns to the value of $18^{\circ}$.

Knowing the values of the hydrodynamic coefficients and, it is calculated by formulas (2) and (3), respectively, the loadbearing and resistance forces [6].

$$
\begin{aligned}
& F_{L}=\frac{1}{2} C_{L} \rho V_{\infty}^{2} S_{p}, \\
& F_{D}=\frac{1}{2} C_{D} \rho V_{\infty}^{2} S_{p},
\end{aligned}
$$

and formula (4) provides us with the hydro-dynamic force acting on the blade (figure 2 (b)).

$$
\begin{aligned}
& F_{x^{\prime}}=-F_{L} \sin \varphi+F_{D} \cos \varphi, \\
& F_{y^{\prime}}=F_{L} \cos \varphi+F_{D} \sin \varphi .
\end{aligned}
$$

Figure 2 (b) shows the modulus of the hydrodynamic force $\vec{F}$, which acts on a blade, as well as its tangential and normal components $F_{x^{\prime}}$ and $F_{y^{\prime}}$, depending on the positioning angle. The following construction parameters of the rotor were considered:

Rotor Radius $\mathrm{R}=2 \mathrm{~m}$;

Height of submerged blade $\mathrm{H}=1.4 \mathrm{~m}$;

The length of the blade (rope) $\mathrm{c}=1.3 \mathrm{~m}$;

Working angle of attack $\alpha=18^{\circ}$;

Number of blades $\mathrm{N}_{\text {bld }}=5$.

Figure 3 (a) shows the moment $T_{r, i}$ developed by a blade according to the positioning angle, the moment being calculated by formula (5), and figure 3 (b) contains the total moment $T_{r \Sigma}$ at the rotor shaft, developed by all blades according to the angle positioning, moment calculated by formula (6).

$$
\begin{aligned}
& T_{r, i}=F_{x^{\prime}} \cdot\left|O O^{\prime}\right|, \\
& T_{r \Sigma}=\sum_{i=1}^{N p a l} T_{r i},
\end{aligned}
$$

Figure 4 shows the total moment $T_{r \Sigma}$ as a function of the positioning angle for three values of the speed of the water current $V_{\infty}: 1 \mathrm{~m} / \mathrm{s}, 1,3 \mathrm{~m} / \mathrm{s}$ and $1,6 \mathrm{~m} / \mathrm{s}$. Figure 6 shows the graph of the moment coefficient $C_{M, \text { ref }}$ as a function of the attack angle $\alpha$.

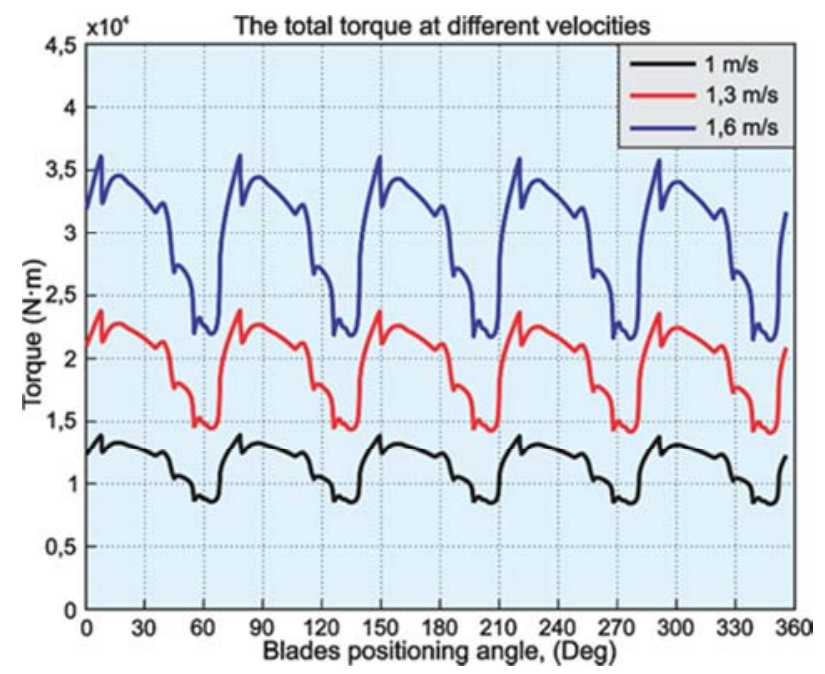

Figure 4. The total torque $T_{r \Sigma}$ at the rotor shaft depending on the positioning angle at different speeds of the water flow. 


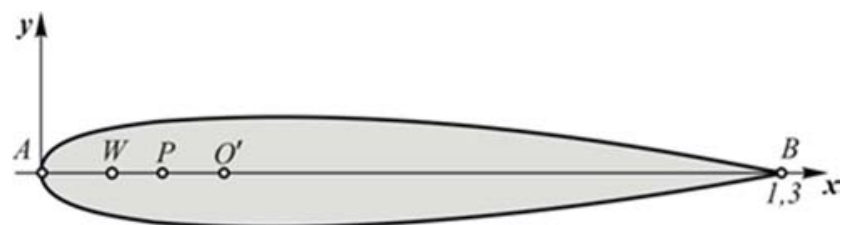

Figure 5. Location of the blade attachment point.

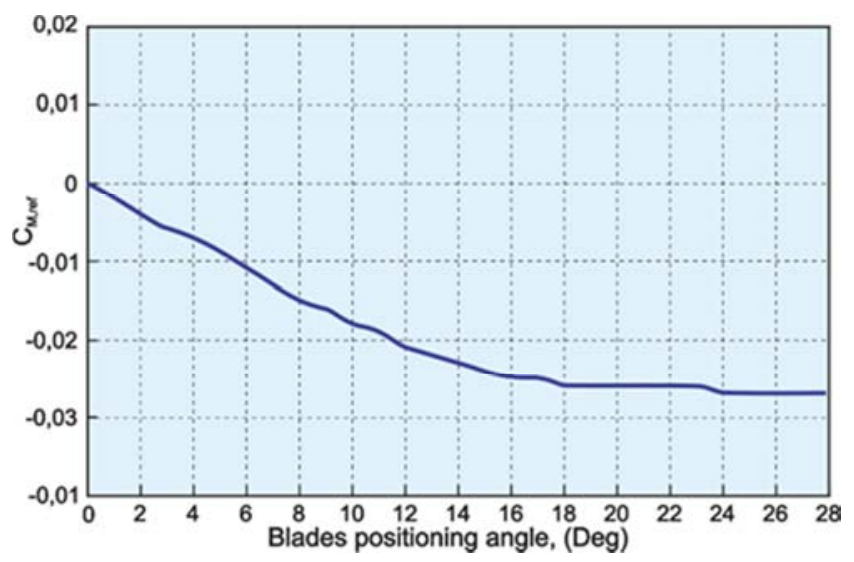

Figure 6. Moment coefficient $C_{M \text {,ref }}$ depending on the angle of attack for the NACA 0016 profile.

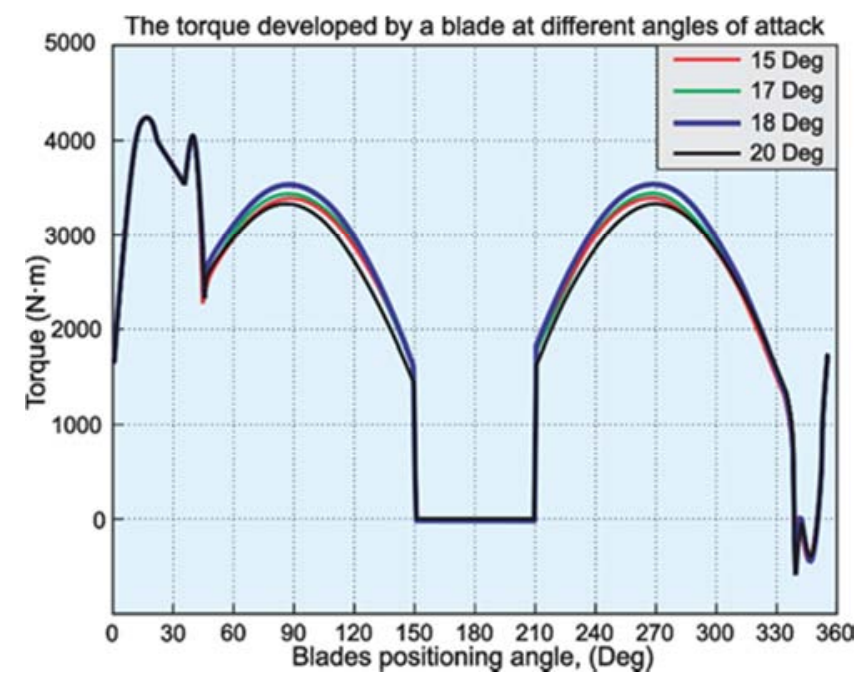

Figure 7. The moment $T_{r}$ i developed by a blade depending on the positioning angle at different values of the angle of attack $\alpha=15^{\circ}, 17^{\circ}, 18^{\circ}$, $20^{\circ}$.

Considering that the hydrodynamic force is not applied at the origin of the blade coordinate system (figure 2 (b)), this force produces a torque, called the pitch moment. This moment is determined from a reference point.

The reference point $\mathrm{P}$, located at a distance $1 / 4$ from the rope, will be considered as a reference point from the attack board (figure 3 (a)), figure 5. For the working values of the attack angle $\alpha=18^{\circ}$ we obtain $C_{M, r e f}=-0,026$. Thus, it follows from relation (1) that $C_{M}=0,0439$.

The torque from the point $\mathrm{P}$ is

$$
M=\frac{1}{2} C_{M} \rho V_{\infty}^{2} c S_{p}=-39,92 N \cdot m,
$$

where $V_{\infty}=1 \mathrm{~m} / \mathrm{s}, \mathrm{c}=1,3 \mathrm{~m}$ and $\mathrm{H}=1,4 \mathrm{~m}$.

The components of the hydrodynamic force in the coordinate system $O^{\prime} x^{\prime \prime} y^{\prime \prime}$ are provided by the relations (4). Using $F_{L}$ and $F_{D}$ values obtained previously, we have:

$$
\begin{aligned}
& F_{x^{\prime \prime}}=1601,2 \mathrm{~N}, \\
& F_{y^{\prime \prime}}=-413,8 \mathrm{~N} .
\end{aligned}
$$

In this case

$$
\left|O^{\prime} P\right|=|M| /\left|F_{x^{\prime \prime}}\right|=0,0249 m \approx 25 \mathrm{~mm}
$$

In order to ensure the stability of the blade movement, the fixing point $W$ must be chosen in the range $25 \mathrm{~mm} \leq\left|O^{\prime} W\right| \leq H$, where $H_{\min } \leq H \leq H_{\max }$. The values $H_{\min }$ and $H_{\max }$ are taken only if the frictional force, which occurs in the kinematic torques of the orientation mechanism, is minimal.

To determine the optimal working attack angle, we calculate the value of the moment developed by a blade and the total moment for several values of the angle of attack, namely: $\alpha=15^{\circ}, 17^{\circ}, 18^{\circ}, 20^{\circ}$ (figure 7 , figure 8 ). Thus, the attack angle for the blade with the hydrodynamic profile NACA 0016 was chosen $\alpha=18^{\circ}$.

The rotor performance with 3,4 and 5 blades was also analyzed. Thus, the total moment developed at the rotor shaft was calculated, the results being presented in figure 9 .

\section{Development and Design of the Rotor Blade Orientation Mechanism Depending on the Positioning Angle $\varphi$}

\subsection{Variation of the Blade Angle of Attack and Ensuring Maximum Efficiency of Energy Conversion of Water Currents}

Increasing the efficiency of the kinetic energy conversion of the water flow both by contributing to the formation of the summary torque of the blades in the transition zone from the upstream area to the downstream area, and by positioning the blades according to the flow rate of the water flow, leads to the increase of the hydrodynamic forces developed by each blade and to the concomitant decrease of the hydraulic resistance forces to the rotation of the blades.

Figure 10 shows the main diagram $[6,13,15,17]$ of the mechanism of continuous orientation of the blades with hydrodynamic profile in relation to the direction of fluid flow. 


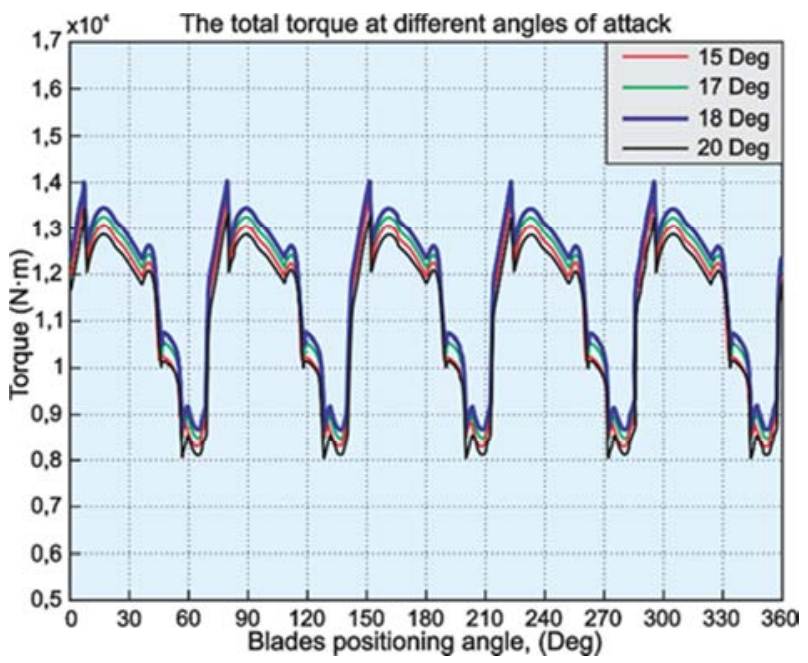

Figure 8. The total moment $T r, \sum$ depending on the positioning angle at different values of the attack angle $\alpha=15^{\circ}, 17^{\circ}, 18^{\circ}, 20^{\circ}$.

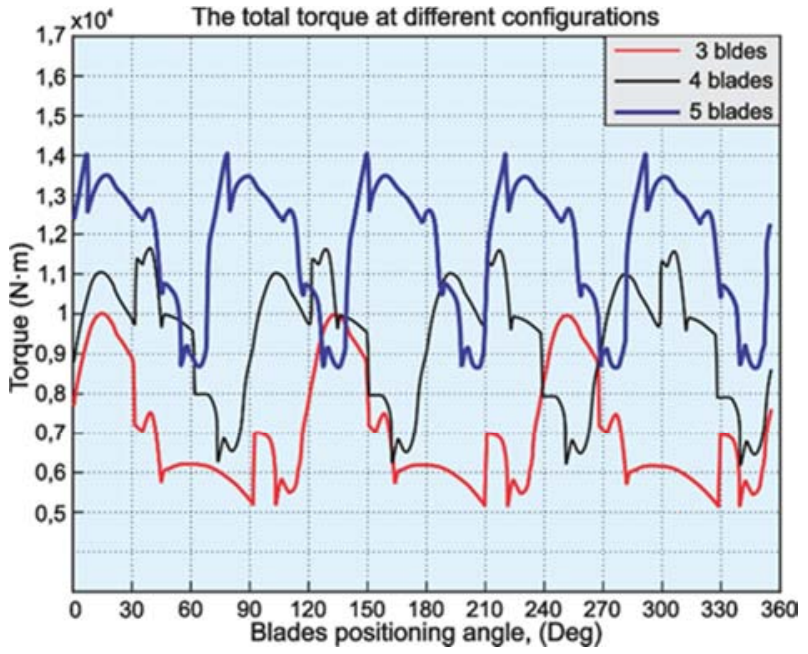

Figure 9. The total torque $T r, \sum$ developed at the rotor shaft with 3, 4 and 5 blades depending on the positioning angle.

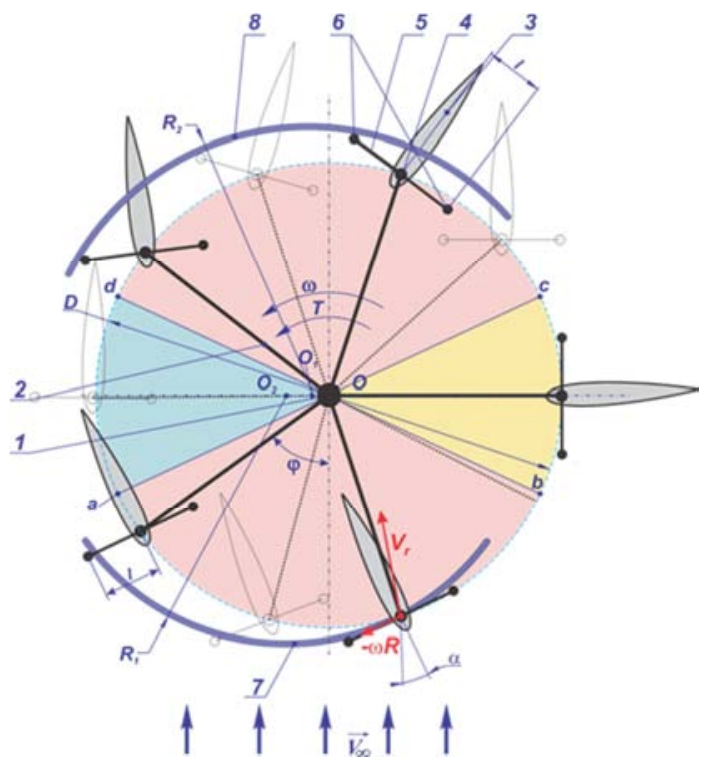

Figure 10. The main diagram of the continuous blade orientation mechanism in relation to the direction of fluid flow.
The circular profile guide with radius $R_{1}$ can be located upstream $O a b$ with the origin in the center $O_{1}$ moved at a distance $O O_{l}$, the circular profile guide with radius $R_{2}$ can be located downstream $\mathrm{Ocd}$ with the origin in the center $\mathrm{O}_{2}$ moved at a distance $\mathrm{OO}_{2}$, and the rectilinear profile guide can be placed in the upstream-downstream transition zone at an angle of inclination $\beta$ to the direction of fluid flow, with the possibility of rolling one of the rotating bodies on the guide surface.

Each half-axis can be placed on the axis of symmetry of the hydrodynamic profile at the distance $B W$ from the blade of the blade determined by the relation:

$$
B W=0,25 c-k ;\left[\Delta<k \leq k_{\max }\right]
$$

where $c$ is the length of the blade rope; $k$ - linear dimension, which determines the provision of the condition for stabilizing the positioning of the blade in the fluid $R_{k}>0 ; \Delta=$ (25...40) $\mathrm{mm}$ when changing the length of the corresponding c string from $800 \ldots 1300 \mathrm{~mm} ; k_{\max }$ - the maximum linear dimension determined from the condition of the allowable frictional forces in the kinematic torque rotating bodies guide.

The rotating bodies can be mounted in rods with the possibility of changing the distance $l$ of their location from the axis of the semi-axes of the blades depending on the flow rate of the fluid.

The radii of the guides $R_{1}, R_{2}$, the displacements of their origins $\mathrm{OO}_{1}$ and $\mathrm{OO}_{2}$, the angle of inclination $\beta$ of the rectilinear guide (9) (figure 11 (a)) with respect to the direction of fluid flow, as well as the location $l$ of the rotating bodies from the axis the half-axes of the blades can be taken in relation to the diameter $D$ of the rotor, so that the blades are positioned below the variable attack angle $\alpha$ :

Upstream $O a b \alpha=12^{\circ} \ldots 25^{\circ}$

Downstream $\operatorname{Ocd} \alpha=90^{\circ} \ldots 25^{\circ}$,

In the upstream-downstream transition zone $O b c \alpha=$ $12^{\circ} \ldots 90^{\circ}$

And in the downstream-upstream transition zone Oda the blades are voluntarily positioned by the fluid flow $\alpha=0^{\circ}$.

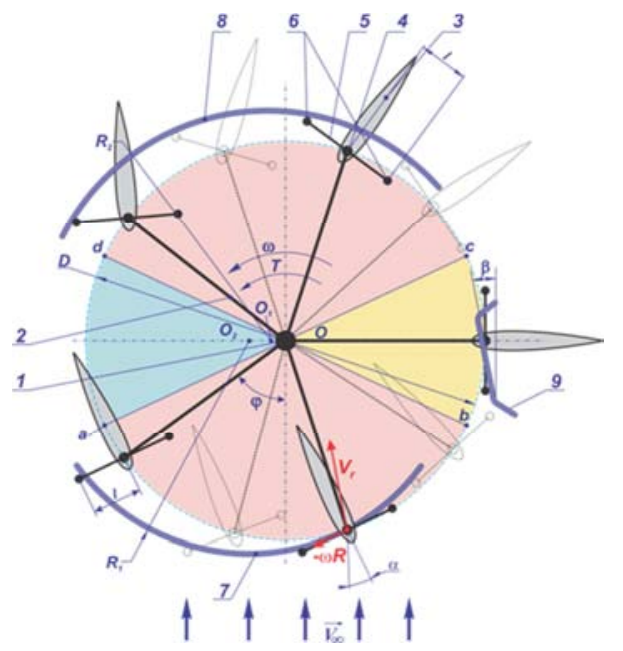

(a) 


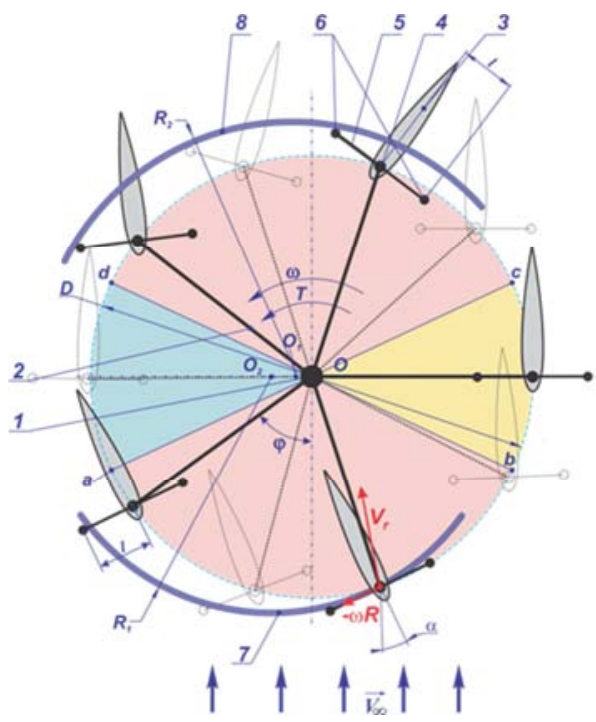

(b)

Figure 11. Main diagram of the mechanism of continuous orientation of the blades in relation to the direction of flow of the fluid for the speed of water currents $V \leq 1,0 \mathrm{~m} / \mathrm{s}$ (a) and $V \geq 1,0 \mathrm{~m} / \mathrm{s}$ (b).

The hydraulic station provides the following advantages:

The profile and the location of the guides are executed so that the individual positioning of each blade takes place differently depending on the blade-fluid interaction area taking into account the flow rate of the water flow;

Upstream location $O a b$ relative to the rotor of a circular profile guide with radius $R_{I}$ and origin in the center $O_{I}$ displaced at a distance $O O_{l}$, downstream $O c d$ of another circular profile guide with radius $R_{2}$ and origin in the center $\mathrm{O}_{2}$ displaced at a distance $\mathrm{OO}_{2}$ and location in the upstreamdownstream transition zone of a guide with a rectilinear profile located at an angle $\beta$ ensures, by interaction with the

rotating bodies of the rods mounted on the blade semiaxes, a differentiated positioning of the blades, so that the hydrodynamic forces developed by the blades in all three areas $O a b, O c d$ and Oda contribute to the formation of the torque at the rotor axis, which leads to the increase of the energy conversion efficiency;

the location of the blade semi-axes on the axis of symmetry of the hydrodynamic profile at the $B W$ dimension on board the blade determined by the relation (10) allows the stabilization of the positioning of the blades in the fluid starting from the condition $R_{k}>0$;

Mounting the rotating bodies in rods with the possibility of changing their distance $l$ from the axis of the semi-axes of the blades ensures the repositioning of the blades depending on the flow rate of the water flow, and implicitly ensures the increase of the conversion efficiency;

The shape of the guides and their location, taken in relation to the diameter of the rotor $D$, as well as the possibility of considering the influence of the flow velocity of the water flow on the correct positioning of the blades ensure the orientation of the blades at variable angles of attack:

Upstream $O a b \alpha=12^{\circ} \ldots 25^{\circ}$,
Downstream Ocd $\alpha=90^{\circ} \ldots 25^{\circ}$,

In the upstream-downstream transition zone $O b c \alpha=$ $12^{\circ} \ldots 90^{\circ}$;

This positioning ensures an increased energy conversion by efficiently capitalizing on the hydrodynamic forces developed by the blades and reducing the hydraulic resistance forces acting on the blades when they rotate around the main axis of the hydraulic rotor.

As for the hydrodynamic rotor, in order to ensure a maximum efficiency of conversion of the kinetic energy of each blade in different phases of rotation, a mechanism for orienting the blades towards the water currents with two configurations has been developed:

1. Positioning of the rotor blades according to the positioning angle $\varphi$ for the speed of water currents $V \leq 1,0$ $\mathrm{m} / \mathrm{s}$ (figure 11 (a));

2. Positioning of the rotor blades according to the positioning angle $\varphi$ for the speed of water currents $V \geq 1,0$ $\mathrm{m} / \mathrm{s}$ (figure 11 (b)).

The difference is the positioning of the blade in the neutral zone at the angle of attack $\alpha=90^{\circ}$ at the speed of water currents $V \leq 1,0 \mathrm{~m} / \mathrm{s}$ using the guide 9 , and in the second case the auto positioning of the blade in the neutral zone at the angle of attack $\alpha=0^{\circ}$ takes place and the steering mechanism 9 is removed from the construction of the steering mechanism. A key mechanism is the orientating mechanism.

Based on the theoretical elaborations, the geometric parameters are identified: the radii of curvature of the guides $R_{l}$ and $R_{2}$, placement of the centers of their radii of curvature $O$, the placement of the centers of their radii of curvature $O O_{1}$ and $O O_{2}$, the angle of inclination $\beta$ of the guide with rectilinear profile (figure 12), as well as the geometric parameters of the orientation mechanism. and blade stabilization with hydrodynamic profile.

Figure 12 shows the kinematic diagram of the blade with hydrodynamic profile with the constructive parameters of the mechanism of orientation and stabilization of the blade in the fluid. When the blade 3 interacts with the fluid, the hydrodynamic force $F_{x}^{\prime}$ communicates to it a rotational movement $\omega$ around the main axis 4 of the rotor. The blade 3 is positioned relative to the direction of the fluid under the angle determined by rolling on the surface of the guide 7 of the rotating body 6 mounted at the end of the rod 5 fixedly fixed on the half-axis 2 of the blade. To ensure the blade 3 positional stability in the fluid for any angle $0<\varphi<2 \pi$ the semi-axis 2 is placed on the axis of symmetry of the hydrodynamic profile at the distance on board BW determined by the relation (10).

The position of the blade 3 in the fluid for any $\varphi$ is stable if: $\Delta<k \leq k_{\max }$, where $k_{\max }$ - the maximum linear dimension determined from the condition of the allowable friction forces in the kinematic torque rotating body - guide.

The mentioned constructive parameters vary depending on the flow rate of the fluid $V_{\infty}$. 


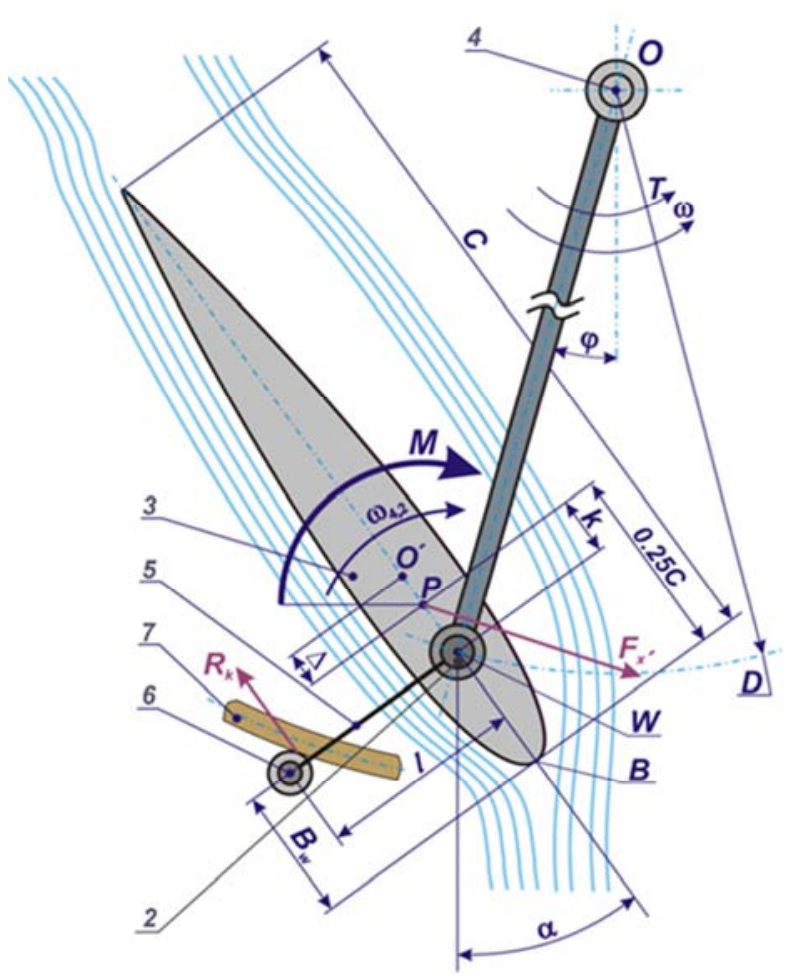

Figure 12. Kinematic scheme of the hydrodynamic blade with the constructive parameters of the mechanism of orientation and stabilization of the blade in the fluid.

\subsection{Development of the Kinematic Link Mechanism of the Blade with the Multipal Rotor and of the Guide Mechanism}

Following the previous research on the kinematic connection mechanism of the blade with the multipal rotor, the kinematic connection mechanism of the blade with the multipal rotor and the guidance mechanism were designed in the Autodesk MotionInventor software (figure 13 (a, b, c)) $[11,12,17]$. Their manufacture took place at the INCOMAS SA plant and the MOLDOVAHIDROMAȘ SA plant in Chisinau.

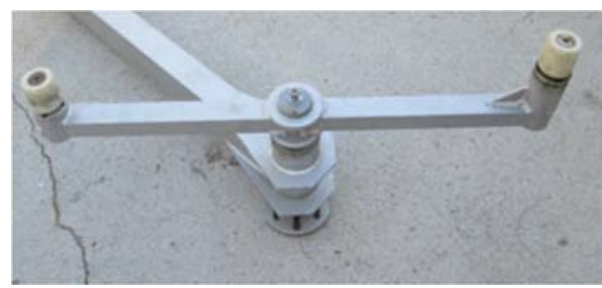

(a)

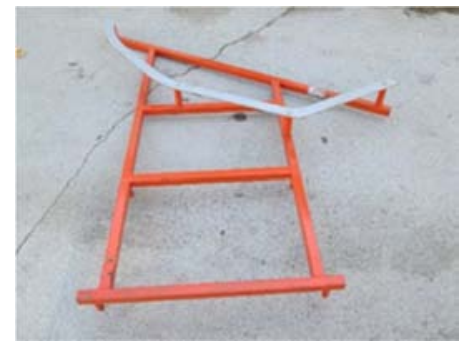

(b)

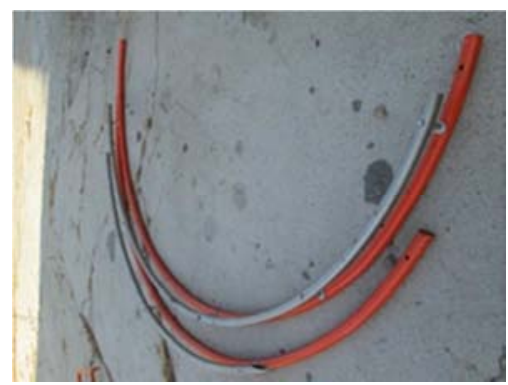

(c)

Figure 13. The kinematic link mechanism of the blade with the multi-blade rotor (a), the guide mechanism composed of the rectilinear guide (b) and the curvilinear guides (c).

\section{Development, Design and Manufacture of Flow Micro Hydropower Plants}

In the elaboration of the microhydropower plants, the experience gained at the stage of "research - design manufacture" of the pilot station exposed in $[7,9,11,14,15$, 17] was used.

The efficiency of operation of micro-hydropower plants by individual consumers for a given destination depends both on the correct choice of the constructive configuration of the micro-hydropower plant and on the functional characteristics of the component aggregates.

In order to meet the requirements of consumers of microhydropower plants and increase the efficiency of the conversion of the kinetic potential of running water in their area of operation, constructive and functional concepts based on modular assembly principles have been developed, including:

MHCF with hydrodynamic rotor for converting the kinetic energy of direct river water into mechanical energy - for water pumping (MHCF D4x1,5 M/PSS);

MHCF with hydrodynamic rotor for the conversion of kinetic energy of river water into electricity (MHCF D $4 x 1,5$ $E)$;

MHCF with hydrodynamic rotor for the conversion of kinetic energy of river water into electrical and mechanical energy ( $M H C F D 4 x 1,5 \mathrm{ME} / \mathrm{CH})$;

MHCF with hydrodynamic rotor for converting the kinetic energy of river water into mechanical energy at low speeds (MHCF D4x1,5 ME/PSS)).

The mentioned micro-hydropower plants, modularly designed, allow the modification of the destination and the functional characteristics by replacing some units with others (generator, pump, blades with another hydrodynamic profile, rotor with 3 or 5 blades).

For the mentioned microhydropower plants, 2 types of rotors with 3 and 5 blades were developed. The installed power of micro hydropower plants with a diameter $D=4 \mathrm{~m}$, the height of the blades submerged in water $h=1.4 \mathrm{~m}$ and the length of the blade cord $c=1.3 \mathrm{~m}$ at the water flow speed $V=1-2 \mathrm{~m} / \mathrm{s}$ can be within $P=2-19 \mathrm{~kW}$. Figure 14 (a) 
shows the industrial prototype of the 5-blade rotor micro hydropower plant.

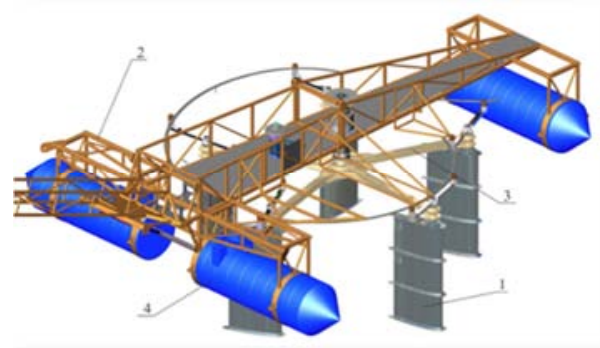

(a)

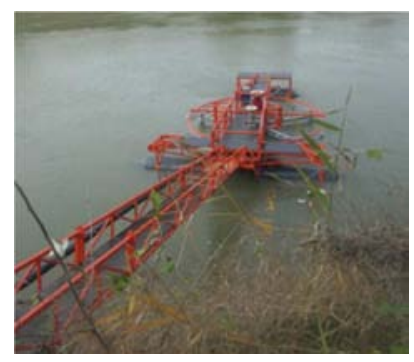

(b)

Figure 14. Flow micro hydropower plant with 5-blade tilting hydrodynamic rotor with cord length $c=800 \mathrm{~mm}$, submerged height $h=1600 \mathrm{~mm}$ and screens for directing fluid flow (a). Industrial prototype of the micro hydropower plant installed on the test site on the Prut River (com. Stoienesti, Cantemir) (b).

Based on research on the hydrodynamic rotor with blade lengths $c=1300 \mathrm{~mm}$ it was found that at speed $V=1.2-1.3$ $\mathrm{m} / \mathrm{s}$ the turbulence of the water flow caused by the upstream blade influences the neighboring blade in the downstream area. Analyzing the results of CFD simulations for the speed of water currents $V>1.3 \mathrm{~m} / \mathrm{s}$, the profile of the blade with cord length $c=800 \mathrm{~mm}$ was elaborated. For the first time, it was proposed to build hydrodynamic blades equipped with screens to direct the flow of fluid along the cord. This technical solution helps to reduce the negative influence on the conversion efficiency of the boundary layer separation [6, 7, 17]. Figure 14 (b) shows the industrial prototype of the micro-hydropower plant with tipping rotor with blades with cord length $c=800 \mathrm{~mm}$ and height $h=1600 \mathrm{~mm}$ equipped with screens.

Based on the elaborated technical documentation, the industrial prototypes of the micro-hydropower plants were manufactured (figure $14(a, b))$.

\section{Conclusions}

Based on the results of scientific research, Autodesk Motion Inventor, Solid Works software were designed and 3 types of MHCF modularly designed with different application areas were manufactured. Increasing the efficiency of the kinetic energy conversion of the water flow both by contributing to the formation of the summary torque of the blades in the transition zone from the upstream area to the downstream area, and by positioning the blades according to the flow rate of the water flow, leads to the increase of the hydrodynamic forces developed by each blade and to the simultaneous decrease of the hydraulic resistance forces when the blades rotate.

The proposed hydrodynamic rotors and the technical solutions developed as a result of CFD simulations, meant to increase the efficiency of energy conversion in MHCF, have been protected with 11 patents.

A particularly important role for households located near the Nistru, Prut and Răut rivers will belong to the use of micro hydropower plants for the conversion of kinetic energy of low power water (up to $10 \mathrm{~kW}$ ). As an advantageous premise for the use of micro-hydropower plants is the fact that a micro-hydropower plant can provide the consumer with electrical or mechanical energy 24 hours a day. Thus the efficiency of using a micro hydropower plant is much higher. It is also necessary to take into account the higher energy density of running water.

\section{Acknowledgements}

The article was developed and financed within the State Program project no. 85 - PS.

\section{References}

[1] I. Bostan, A. Gheorghe, V. Dulgheru, I. Sobor, V. Bostan, A. Sochirean. Resilient Energy Systems. Renewables: Wind, Solar, Hydro. Ed. Springer, VIII, 507 p. 2013. ISBN 978-94007-4188-1.

[2] I. Bostan, V. Dulgheru, I. Sobor, V. Bostan, A. Sochireanu Renewable Energy Conversion Systems. Ed. "Tehnica Info, Chișinău, 592 p. (2007). ISBN 978-995-63-076-4.

[3] I. Bostan, V. Dulgheru, V. Bostan, R. Ciupercă. Anthology of Inventions: renewable energy conversion systems. Vol. 3. Ch.: Bons Offices. 2009. - 458 p. - ISBN 978-9975-80-283-3.

[4] I. Bostan, A. Gheorghe, V. Dulgheru, V. Bostan, A. Sochireanu, I. Dicusară. Conversion of Renewable Kinetic Energy of Water: synthesis, Theoretical Modeling, and Experimental Evaluation. Energy Security: // International and Local Issues, Theoretical Perspectives, and Critical Energy Infrastructures (NATO Science for Peace and Security Series C: Environmental Security). - Published by Springer, 2009. - Pp. 125-176. - ISBN 978-94-007-0718-4.

[5] I. Bostan, V. Dulgheru, I. Sobor, V. Bostan, A. Sochireanu ş. a. Energy, environment, economy, resources, globalization. Harnessing renewable energy sources in Moldova. - Bucureşti : Ed. AGIR., Vol. VI. 2009. - Pp. 153-203. - ISBN 978-973720-263-5.

[6] I. Bostan, V. Dulgheru, V. Bostan, A. Sochireanu, O. Ciobanu, R. Ciobanu. Patent 3845 (MD), CIB F 03 B 13/00; F 03 B 7/00; F 03 B 13/18; F 03 B 13/22; F 03 B 17/06. Hydraulic station / U. T. M. Publ. BOPI - 2009. - Nr. 2.

[7] V. Bostan, O. Ciobanu, V. Dulgheru, A. Sochireanu, M. Vaculenco, V. Gladîș. Patent 4235 (MD), F03B13/00; F03B7/00; F03B13/18. Hydraulic turbine / U. T. M. Publ. 30.06.2013, BOPI nr. 6/2013. 
[8] I. Bostan, V. Dulgheru, V. Bostan Micro hydropower plant with rotor's pintle and hydrodynamic profile of blades // The 13th World Congress in Mechanisms and Machine Science, June 19-25, 2011. - Guanajuato, 2011. - Pp. A29-605.

[9] I. Bostan, V. Bostan, V. Dulgheru, O. Ciobanu, R. Ciobanu, P. Chiriță. Argumentation of the Optimal Hydrodynamic Profile of Blades of the Flow Microhydrostation Rotor's. "HIDRAULICA", No. 4/2018. Magazine of Hydraulics, Pneumatics, Tribology, Ecology, Sensorics, Mechatronics. Pp. 84-89. ISSN 1453-7303.

[10] I. Bostan, V. Dulgheru, V. Bostan, A. Sochireanu, N. Trifan, I. Dicusara, O. Ciobanu, R. Ciobanu. A micro/hydropower station for the conversion of flowing water kinetic energy // Environmental Engineering and Management Journal, Universitatea Transilvania din Braşov, România, 10-12 Noiembrie, 2011. - Pp. 1033-1040. IF 1,435.

[11] I. Bostan, V. Dulgheru, V. Bostan, O. Ciobanu. Microhidropower station for kinetic energy conversion of flowing whater with hydrodinamic rotor. Proceedings of the International Conference on Industrial Power Engineering EI 2014, The 9-th Edition. Bacău: Alma Mater, 2014, p. 31-36. ISSN 2069-9905.

[12] I. Bostan, V. Dulgheru, V. Bostan, O. Ciobanu. Microhidropower station for kinetic energy conversion of flowing whater. Proceedings of the 8th International Conference on electromechanical and power systems SIELMEN 2011. Craiova - Iaşi: Romania, Chişinău: Republic of Moldova. 2011, p. 254-258.

[13] V. Bostan. Numerical and computational analysis of hydrodynamic effects in the micro-hydro power station. In: Meridian Ingineresc, 2012, nr. 2, p. 16-27. ISSN 1683-853X.

[14] V. Bostan, I. Bostan, V. Dulgheru, M. Vaculenco, V. Odainâi, O. Ciobanu. Mathematical modeling of hydrodinamic processes in the rotors of flow micro-hydropower plants. 1013 October 2017, Iassy-Chisinau. Proceedings, IEEE. Pp. 302307. DOI: 10.1109/SIELMEN. 2017.8123337. Electronic ISBN: 978-1-5386-1846-2. ISBN: 978-1-5386-1847-9.

[15] V. Bostan, I. Bostan, V. Dulgheru, O. Ciobanu, R. Ciobanu, V. Gladâș. Developing modified hydrodynamic rotor for flow small hydro / Nearly Zero Energy Communities. Proceedings of the Conference for Sustainable Energy (CSE) 2017. Editors: Vișa I., Duța A. Springer, Pp. 490-499, ISBN 978-3-31963214-8.

[16] I. Bostan, V. Bostan, V. Dulgheru. Numerical modelling of the interaction between fluid flow and working elements // Conference on Sustainable Energy. Proceedings, 3-5.07.2008. - Braşov, 2008. - Pp. 381-386. ISBN 978-973-598-316-1.

[17] I. Bostan, V. Dulgheru, V. Bostan ş. a. Hydropower serving rural consumers. - Ch.: Bons Offices, 2013. -52 p. 